\title{
New Numerical Procedure for Determination of Elastic Curve of Statically Determinate and Indeterminate Beams with Variable Cross Sections
}

\author{
István Bíró
}

University of Szeged, Faculty of Engineering, Mars tér 7, H-6724 Szeged, Hungary, biro-i@mk.u-szeged.hu

\begin{abstract}
In this paper a new numerical procedure is developed for calculating the inclination angle and deflection as initial conditions of the end points of statically determinate and indeterminate beams. The method is based on the topology comparison of simple (hinge-roller combination) supported beam and a resemblant cantilever beam. Assuming that the support reactions of the beam are active forces, the virtual displacements at the points of the reaction forces are calculated. Based on these values the inclination angle is calculated. Several examples are considered and the suggested in this paper, while the procedure is applied for various types of structures and loadings. The results, obtained by the suggested numerical procedure, are compared with analytical ones, and they are in good agreement.
\end{abstract}

Keywords: elastic curve; beams of variable cross section; initial guess for slope and deflection

\section{Introduction}

Beam-like members [1] such as shafts, levers, frame components, beam structures, etc. are regularly designed and constructed in the field of mechanical and civil engineering. Before construction or fabrication of the structure the knowledge of the integrity, i.e., the deflection and inclination angle of the structure, is pertinent. The inclination angle has also the importance in detection of the modal parameters of the beam which seem to be of great significance in bridge and other structural health detection and damage identification [2]. For various values of inclination angles the failure modes of components are computed and the evaluation of failure with increasing the angle is studied. Inclination angles are obtained applying the theoretical approach or using experimental methods. For example the inclination angle is measured by Yang and Qin [3] with the inclinometer. However, the experimental procedure is complex and connected with troubles and costs. 
To overcome these problems numerous methods for determination of the inclination angle are developed [4-10]. Thus, the large deflection of a simply supported beam loaded in the middle has been studied analytically by using the exact solutions and the finite element method. In practice, the inclination angles are computed applying the commercial simulation packages. Recently, a computational tool, CABDA, has been designed and developed on MATLAB where the algorithm is based on analytic equations of beam deflection [1]. The program is tested on steel and brass rectangular beams and the results are compared with those obtained experimentally and by simulation. Some differences in the results have been observed. The error in numerically obtained solutions is explained with the fact that the program uses the linear structure theory, which is not applicable for strongly nonlinear systems. If the deformation of the beam is small, the use of linear theory for determining the shape of the elastic curve and the inclination angle is appropriate. However, the results obtained according to the linear theory are not convenient for the beam with large deformation and strong nonlinearity. In these special cases, modification in the numerical solving procedure is necessary and the nonlinear structure theory has to be included.

Recently, some analytical investigations on calculation of inclination angle of strong nonlinear structures were carried out and published. Thus, the inclination angle of a prismatic cantilever beam subjected to a combination of inclined end force and tip moment was computed by Abu-Alshaikh et al. [11]. The nonlinear theory of bending and the exact expression of the curvature are used. Based on an elliptic integral formulation, an accurate numerical solution is obtained. Comparing with previously published results, the accuracy of numerical solution obtained with the method is more accurate. In terms of Jacobi elliptic functions, the solution of equilibrium configuration of an elastic beam, subjected to threepoint bending, is given by Batista [12]. Results obtained numerically are compared with those of other authors. The relationship between force and deflection of a thin elastic beam is given approximately as a polynomial function. The Galerkin method is used to obtain an approximate force-deflection characteristic of the [13].To validate the result the exact solution and that from the finite element method are used. The analytic Homotopy Perturbation Method (HPM) is adopted by Hatami et al. [14] for predicting the deflection of a cantilever beam subjected to static co-planar loading. The analytical solution procedure is applied for a Reissner's beam underforce acting at the midpoint be-tween two supports [15]. Comparing HPM through numerical results it is demonstrated that HPM can be a high efficiency procedure for computing the deflection. However, the procedure is rather complex and the computation requires significant time. Machado et al. [16] introduced a weighted algorithm, based on the reduced differential transform method. The proposed scheme considers the initial and boundary conditions simultaneously for obtaining a solution of the equation. 
To overcome the computation problem, the aim of this paper is to introduce a new procedure for calculating the inclination angle and deflection as initial conditions of the end points of statically determinate and indeterminate beams. The numerical procedure would involve less computational time compared with other techniques available in literature. The method is based on a topology comparison of a simply supported beam and its resemblant or to say "modified" cantilever beam. Assuming that the support reactions of the beam are active forces, the virtual displacements at the points of the reaction forces are calculated. Based on these values the inclination angle and deflection of the endpoint of the beam as initial conditions can be calculated. Several examples are considered and the suggested in this paper, while the procedure is applied for various types of structures and loadings. The results, obtained by the suggested numerical procedure, are compared with analytical ones, and they are in good agreement.

As problem solving technique this numerical method can be offered for engineers. It can be treated as one of problem solving techniques for engineers published by Horvath and Rudas [17]. The demonstrated method can be applied to metamaterial beams as well published by Cveticanin and Mester [18].

The paper is divided into five sections. After the introduction, in Section 2, the theorem of calculation of the inclination angle at the end point of the beam is introduced and proved. In Section 3, the procedure of transforming the boundary value problem into initial problem for a simply supported to a cantilever beam with variable cross-section is presented. The procedure is applied on examples. The paper ends with conclusions.

\section{Procedure for Computing of the Approximate Inclination Angle}

Theorem 1. In case of linear model of simple supported beams with two consoles loaded at arbitrary places by concentrated and/or distributed forces and/or couple of forces the inclination angle of free end of the console on the left side is

$\varphi_{C}=-\frac{y_{B}-y_{A}}{l}$,

where 1 is the distance between the supports, $\mathrm{y}_{\mathrm{A}}$ and $\mathrm{y}_{\mathrm{B}}$ are the elastic deflections at cross-section A and B of the "modified" beam. The "modified" beam is clamped at cross-section $\mathrm{C}$, with an identic active load system compared to the original model.

It must be mentioned that the calculated reaction forces are considered active forces in the modified version of the model. Applied notations can be seen in Figure 1. 
There are 6 different loading components of the beam in Figure 1 such as concentrated forces and couple of forces acting on consoles on the right or left side or between the supports.

To proof of the theorem/equation (1) is investigated with regard to the different load-ings of the consoles, the effective span of beam together with the uniform and variable cross-section. Theorem/equation (1) is proved for each load cases. Based on the superposition, the principle of the theorem/equation (1) is true for any simple supported beams loaded by concentrated and couple of forces at any places.

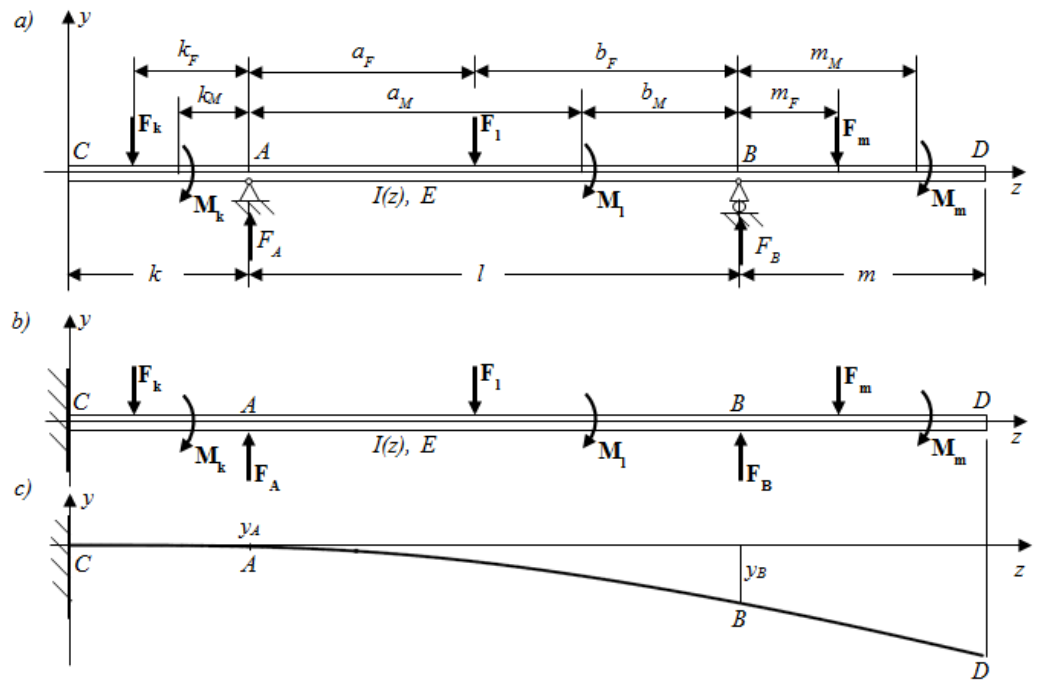

Figure 1

(a) Scheme of simple supported beam with two consoles loaded at arbitrary places by concentrated forces and couple of forces (notations to the proof); (b) „Modified” beam clamped at cross section C;

(c) Shape of the elastic curve in case of modified beam $\left(\varphi_{\mathrm{Cmod}}=0, \mathrm{y}_{\mathrm{Cmod}}=0\right)$

Proof of Theorem 1. The proof of the theorem (1) is done on examples of beams with various types of loadings shown in Figures 1, 12-17. The formula for calculating the elastic curves, $\mathrm{y}(\mathrm{z})$, of beams of variable cross-section and loaded with bending moment $\mathrm{M}(\mathrm{z})$ is

$E I(z) \frac{y^{\prime \prime}(z)}{\left(1+y^{\prime 2}(z)\right)^{\frac{3}{2}}}=-M(z)$,

where $\mathrm{EI}(\mathrm{z})$ is flexural rigidity of the beam, E is modulus of elasticity, $\mathrm{I}(\mathrm{z})$ is moment of in-ertia of the cross section about its neutral axis, $M(z)$ represents the bending moment func-tion of the beam, $\mathrm{z}$ is the position coordinate, while $\left({ }^{\circ}\right)=\mathrm{d} / \mathrm{dz}$ and $(")=\mathrm{d}^{2} / \mathrm{dz}^{2}$. In our calculation the linearized version is applied

$E I(z) y^{\prime \prime}(z)=-M(z)$. 
Based on the principle of superposition, the theorem (1) has to be proved. In Figure 1a), a three-part beam, i.e. two consoles and an effective span is shown.

The simple supported beam with two consoles is loaded at arbitrary places by concentrated forces and couple of forces. In Figure 1b), the „modified” beam clamped at cross section $\mathrm{C}$ can be seen. In Figure 1c), the shape of the elastic curve in case of modified beam $\left(\varphi_{\mathrm{Cmod}}=0, \mathrm{y}_{\mathrm{Cmod}}=0\right)$ is shown.

In Table 1 the results for different types of supported beams loaded with various types of loading are presented. The applied notations in the Table 1 and Figures 12-17 are:

- $\mathrm{F}_{\mathrm{A}}$ and $\mathrm{F}_{\mathrm{B}}$ are reaction forces in cases of active loading,

- $\mathrm{y}_{\mathrm{A}}$ and $\mathrm{y}_{\mathrm{B}}$ are the elastic deflections of cross section A and B in case of the „modified” beam,

- $\quad$ and $\varphi_{\mathrm{C}}$ is the inclination angle calculated according to equation (1).

Table 1

Summary of physical quantities to prove the presented theorem in case of beam of uniform crosssection

\begin{tabular}{|c|c|c|c|}
\hline Model & $\mathbf{F}_{\mathbf{A}}$ & $\mathbf{F}_{\mathbf{B}}$ & $\mathbf{y}_{\mathbf{A}}$ \\
\hline Figure 12 & $\frac{F_{k}\left(k_{F}+l\right)}{l}$ & $\frac{F_{k} k_{F}}{l}$ & $-\frac{F_{k} k_{F}^{3}}{6 I E}$ \\
\hline Figure 13 & $\frac{M_{k}}{l}$ & $\frac{M_{k}}{l}$ & $-\frac{M_{k} k_{M}^{2}}{2 I E}$ \\
\hline Figure 14 & $\frac{F_{l} b_{F}}{l}$ & $\frac{F_{l} a_{F}}{l}$ & 0 \\
\hline Figure 15 & $\frac{M_{l}}{l}$ & $\frac{M_{l}}{l}$ & 0 \\
\hline Figure 16 & $\frac{F_{m} m_{F}}{l}$ & $\frac{F_{m}\left(m_{F}+l\right)}{l}$ & 0 \\
\hline Figure 17 & $\frac{M_{m}}{l}$ & $\frac{M_{m}}{l}$ & 0 \\
\hline
\end{tabular}

\begin{tabular}{|l|c|c|}
\hline Model & у & 甲C \\
\hline Figure 12 & $-\frac{F_{k}\left(k_{F}+l\right) k_{F}\left(k_{F}+2 l\right)}{6 I E}$ & $-\frac{F_{k} k_{F}\left(3 k_{F}+2 l\right)}{6 I E}$ \\
\hline Figure 13 & $-\frac{M_{k}\left(3 k_{M}^{2}+6 k_{M} l+2 l^{2}\right)}{6 I E}$ & $\frac{M_{k}\left(l+3 k_{M}\right)}{3 I E}$ \\
\hline Figure 14 & $-\frac{F_{l} a_{F} b_{F}\left(a_{F}+2 b_{F}\right)}{6 I E}$ & $\frac{F_{l} a_{F} b_{F}\left(a_{F}+2 b_{F}\right)}{6 l I E}$ \\
\hline Figure 15 & $-\frac{M_{l}\left(2 b_{M}^{2}-2 a_{M} b_{M}-a_{M}^{2}\right)}{6 I E}$ & $\frac{M_{l}\left(2 b_{M}^{2}-2 a_{M} b_{M}-a_{M}^{2}\right)}{6 I I E}$ \\
\hline Figure 16 & $\frac{F_{m} m_{F} l^{2}}{6 I E}$ & $-\frac{F_{m} m_{F} l}{6 I E}$ \\
\hline Figure 17 & $\frac{M_{m} l^{2}}{6 I E}$ & $-\frac{M_{m} l}{6 I E}$ \\
\hline
\end{tabular}


Important remark: $\varphi_{\mathrm{C}}$ inclination angle of the real beam is determined directly by applying the Betti-theorem. The inclination angle in every single case is presented in the last column (Table 1).

In previous load cases it can be seen that the inclination angle of cross-section $\varphi_{C}$ can be determined with the arbitrary lengths of the consoles and the effective span. Moreover, $\varphi_{\mathrm{C}}$ is independent from the positions of the different loadings. In the above-mentioned load cases the flexural rigidity (IE) of the beam is constant along axis $\mathrm{z}$.

It must be mentioned that equation (1) is valid for beams of variable cross-section as well. As it can be seen in Figure 12-17, concentrated and couple of forces act on the left or right consoles or between the supports.

According to this fact, concerning beams of arbitrary variable cross-section, there are different load cases demonstrated in Figure 18. (See in Appendix.) Different types of statically determinate beams of variable cross-sections, with various types of loading, are considered, while the results are presented in Table 2.

Table 2

Summary of physical quantities to prove the presented theorem in case of beams of variable crosssection

\begin{tabular}{|c|c|c|c|}
\hline Model & $\mathbf{F}_{\mathbf{A}}$ & $\mathbf{F}_{\mathbf{B}}$ & $\mathbf{y}_{\mathbf{A}}$ \\
\hline Figure 18 (a) & $\frac{\mathrm{F}(\mathrm{k}+\mathrm{l})}{\mathrm{l}}$ & $\frac{\mathrm{Fk}}{\mathrm{l}}$ & $-\frac{\mathrm{F}}{\mathrm{E}} \int_{0}^{\mathrm{k}} \frac{\mathrm{kz}-\mathrm{z}^{2}}{\mathrm{I}_{\mathrm{k}}(\mathrm{z})} \mathrm{dz}$ \\
\hline Figure 18(b) & $\frac{\mathrm{M}}{\mathrm{l}}$ & $\frac{\mathrm{M}}{\mathrm{l}}$ & $\frac{\mathrm{M}}{\mathrm{E}} \int_{0}^{\mathrm{k}} \frac{\mathrm{k}-\mathrm{z}}{\mathrm{I}_{\mathrm{k}}(\mathrm{z})} \mathrm{dz}$ \\
\hline Figure 18(c) & $\frac{\mathrm{Fb}}{\mathrm{a}+\mathrm{b}}$ & $\frac{\mathrm{Fa}}{\mathrm{a}+\mathrm{b}}$ & 0 \\
\hline Figure 18(d) & $\frac{\mathrm{M}}{\mathrm{a}+\mathrm{b}}$ & $\frac{\mathrm{M}}{\mathrm{a}+\mathrm{b}}$ & 0 \\
\hline
\end{tabular}

\begin{tabular}{|c|c|}
\hline Model & $\mathrm{y}_{\mathrm{B}}$ \\
\hline Figure 18(a) & $-\frac{\mathrm{F}}{\mathrm{E}} \int_{0}^{\mathrm{k}} \frac{(\mathrm{k}+\mathrm{l})-\mathrm{z}^{2}}{\mathrm{I}_{\mathrm{k}}(\mathrm{z})} \mathrm{dz}-\frac{\mathrm{Fk}}{\mathrm{IE}} \int_{0}^{\mathrm{l}} \frac{\mathrm{z}^{2}}{\mathrm{I}_{\mathrm{l}}(\mathrm{z})} \mathrm{dz}$ \\
\hline Figure 18(b) & $\frac{\mathrm{M}}{\mathrm{E}} \int_{0}^{\mathrm{k} k+\mathrm{k}-\mathrm{z}} \frac{\mathrm{M}}{\mathrm{I}_{\mathrm{k}}(\mathrm{z})} \mathrm{dz}+\frac{\mathrm{M}}{\mathrm{IE}} \int_{0}^{\mathrm{l}} \frac{\mathrm{z}^{2}}{\mathrm{I}_{\mathrm{l}}(\mathrm{z})} \mathrm{dz}$ \\
\hline Figure 18(c) & $\frac{\mathrm{Fa}}{(\mathrm{a}+\mathrm{b}) \mathrm{E}} \int_{0}^{\mathrm{b}} \frac{\mathrm{z}^{2}}{\mathrm{I}(\mathrm{z})} \mathrm{dz}-\frac{\mathrm{Fb}}{(\mathrm{a}+\mathrm{b}) \mathrm{E}} \int_{\mathrm{b}}^{\mathrm{a}+\mathrm{b}} \frac{\mathrm{z}^{2}-(\mathrm{a}+\mathrm{b}) \mathrm{z}}{\mathrm{I}(\mathrm{z})} \mathrm{dz}$ \\
\hline Figure 18(d) & $-\frac{\mathrm{M}}{(\mathrm{a}+\mathrm{b}) \mathrm{E}} \int_{0}^{\mathrm{a}} \frac{(\mathrm{a}+\mathrm{b})-\mathrm{z}^{2}}{\mathrm{I}(\mathrm{z})} \mathrm{dz}+\frac{\mathrm{Fb}}{(\mathrm{a}+\mathrm{b}) \mathrm{E}} \int_{\mathrm{a}}^{\mathrm{a}+\mathrm{b}} \frac{((\mathrm{a}+\mathrm{b})-\mathrm{z})^{2}}{\mathrm{I}(\mathrm{z})} \mathrm{dz}$ \\
\hline
\end{tabular}




\begin{tabular}{|c|c|}
\hline Model & $\varphi \mathrm{C}$ \\
\hline Figure 18(a) & $\frac{\mathrm{F}}{\mathrm{E}} \int_{0}^{\mathrm{k}} \frac{\mathrm{z}}{\mathrm{I}_{\mathrm{k}}(\mathrm{z})} \mathrm{dz}+\frac{\mathrm{Fk}}{\mathrm{I}^{2} \mathrm{E}} \int_{0}^{1} \frac{\mathrm{z}^{2}}{\mathrm{I}_{\mathrm{l}}(\mathrm{z})} \mathrm{dz}$ \\
\hline Figure 18(b) & $-\frac{\mathrm{M}}{\mathrm{E}} \int_{0}^{\mathrm{k}} \frac{1}{\mathrm{I}_{\mathrm{k}}(\mathrm{z})} \mathrm{dz}-\frac{\mathrm{M}}{\mathrm{1}^{2} \mathrm{E}} \int_{0}^{1} \frac{\mathrm{z}^{2}}{\mathrm{I}_{\mathrm{l}}(\mathrm{z})} \mathrm{dz}$ \\
\hline Figure 18(c) & $-\frac{\mathrm{Fa}}{(\mathrm{a}+\mathrm{b})^{2} \mathrm{E}} \int_{0}^{\mathrm{b}} \frac{\mathrm{z}^{2}}{\mathrm{I}(\mathrm{z})} \mathrm{dz}+\frac{\mathrm{Fb}}{(\mathrm{a}+\mathrm{b})^{2} \mathrm{E}} \int_{\mathrm{b}}^{\mathrm{a}+\mathrm{b}} \frac{\mathrm{z}^{2}-(\mathrm{a}+\mathrm{b}) \mathrm{z}}{\mathrm{I}(\mathrm{z})} \mathrm{dz}$ \\
\hline Figure 18(d) & $\frac{\mathrm{M}}{(\mathrm{a}+\mathrm{b})^{2} \mathrm{E}} \int_{0}^{\mathrm{a}} \frac{(\mathrm{a}+\mathrm{b})-\mathrm{z}^{2}}{\mathrm{I}(\mathrm{z})} \mathrm{dz}-\frac{\mathrm{Fb}}{(\mathrm{a}+\mathrm{b})^{2} \mathrm{E}} \int_{\mathrm{a}}^{\mathrm{a}+\mathrm{b}} \frac{((\mathrm{a}+\mathrm{b})-\mathrm{z})^{2}}{\mathrm{I}(\mathrm{z})} \mathrm{dz}$ \\
\hline
\end{tabular}

Applied notations in the head of Tables 1 and 2 are the same. The inclination angle $\varphi_{C}$ in all of cases is determined in both ways again.

In Figure 18a)-b) the console is subjected to loads on its left side. Due to the symmetry, it is enough to prove equation/theorem (1) for inclination angle $\varphi_{\mathrm{B}}$. In this case, the beam is clamped at cross section B.

Applying notations of Figure 18a, inclination angle of cross section B of the original beam,

$\varphi_{\mathrm{B}}=\frac{\mathrm{Fk}}{\mathrm{l}^{2} \mathrm{E}} \int_{0}^{\mathrm{l}} \frac{\mathrm{zl}-\mathrm{z}^{2}}{\mathrm{I}(\mathrm{z})} \mathrm{dz}$.

In case of the "modified" beam, i.e. our current beam is clamped at cross section $\mathrm{B}$ and loaded by concentrated force and reaction forces of simple supported beam (Figure 18a) the elastic deflections at cross section A and B can be determined on the basis of the Betti-theorem,

$\mathrm{y}_{\mathrm{A}}=-\frac{\mathrm{Fk}}{\mathrm{IE}} \int_{0}^{\mathrm{l} z \mathrm{l}-\mathrm{z}^{2}} \frac{\mathrm{I}(\mathrm{z})}{\mathrm{dz}}, \quad \mathrm{y}_{\mathrm{B}}=0$.

According to equation (1),

$\varphi_{\mathrm{B}}=-\frac{\mathrm{y}_{\mathrm{A}}-\mathrm{y}_{\mathrm{B}}}{\mathrm{l}}=-\frac{1}{\mathrm{l}}\left[-\frac{\mathrm{Fk}}{\mathrm{IE}} \int_{0}^{\mathrm{l} z \mathrm{zl}-\mathrm{z}^{2}} \mathrm{I}(\mathrm{z}) \mathrm{dz}-0\right]=\frac{\mathrm{Fk}}{\mathrm{I}^{2} \mathrm{E}} \int_{0}^{\mathrm{l}} \frac{\mathrm{zl}-\mathrm{z}^{2}}{\mathrm{I}(\mathrm{z})} \mathrm{dz}$,

which complies with equations (1) and (3).

Applying notations of Figure 18b, inclination angle of cross section B of real beam,

$\varphi_{\mathrm{B}}=-\frac{\mathrm{M}}{\mathrm{1}^{2} \mathrm{E}} \int_{0}^{\mathrm{l}} \frac{\mathrm{zl}-\mathrm{z}^{2}}{\mathrm{I}(\mathrm{z})} \mathrm{dz}$.

In case of the "modified" beam, i.e. - in this case - clamped at cross section B loaded by couple of forces and reaction forces of simple supported beam (Figure $18 \mathrm{~b})$ the elastic deflections at cross-section $\mathrm{A}$ and $\mathrm{B}$ with regard to the Bettitheorem, 
$\mathrm{y}_{\mathrm{A}}=\frac{\mathrm{M}}{\mathrm{lE}} \int_{0}^{\mathrm{l}} \frac{\mathrm{zl}-\mathrm{z}^{2}}{\mathrm{I}(\mathrm{z})} \mathrm{dz}, \quad \mathrm{y}_{\mathrm{B}}=0$.

According to equation (1),

$\varphi_{\mathrm{B}}=-\frac{\mathrm{y}_{\mathrm{A}}-\mathrm{y}_{\mathrm{B}}}{\mathrm{l}}=-\frac{1}{\mathrm{l}}\left[\frac{\mathrm{M}}{\mathrm{l} \mathrm{E}} \int_{0}^{\mathrm{l}} \frac{\mathrm{zl}-\mathrm{z}^{2}}{\mathrm{I}(\mathrm{z})} \mathrm{dz}-0\right]=-\frac{\mathrm{M}}{\mathrm{1}^{2} \mathrm{E}} \int_{0}^{\mathrm{l}} \frac{\mathrm{zl}-\mathrm{z}^{2}}{\mathrm{I}(\mathrm{z})} \mathrm{dz}$

which complies with equations (1) and (6).

Comparing the results, obtained by the Betti-theorem and equation (2), the theorem is proved.

\section{Method of Transformation Boundary Value Problem into Initial Value Problem}

In Chapter 2 the proof of theorem/equation (1) for statically determinate beams with uniform and/or variable cross-sections, loaded by different way, can be seen. $\varphi_{C}$ inclination angle is the initial slope of the statically determinate (original) beam. Based on the superposition principle, the effect of active load components of the beam are independent from each other. Therefore, the theorem/equation (1) is valid independently in the linear dimension.

Based on the theorem/equation (1), the elastic curve of statically determinate beams can be determined by the following steps:

- Calculation of reaction forces,

- Determination of moment function $\mathrm{M}(\mathrm{z})$ of the beam,

- Substitution of the moment function into differential equation (2b),

- Numerical solution of the differential equation with initial conditions $y(0)=0$, $\mathrm{y}^{\prime}(0)=0$. At this step the beam is treated as ,modified”, i.e. it is clamped at cross section $\mathrm{C}$,

- Applying obtained deflections $\mathrm{y}_{\mathrm{A}}$ and $\mathrm{y}_{\mathrm{B}}$ the initial slope, $\varphi_{\mathrm{C}}=-\left(\mathrm{y}_{\mathrm{B}}-\mathrm{y}_{\mathrm{A}}\right) / l$,

- Repeating the numerical process with initial conditions $y(0)=0, y^{\prime}(0)=\varphi_{C}$ values of deflections $\mathrm{y}_{\mathrm{A}}$ and $\mathrm{y}_{\mathrm{B}}$ which are obtained similarly,

- Repeating the numerical process with initial conditions $y(0)=-y_{A}, y^{\prime}(0)=\varphi_{C}$. As a result, the shape of the elastic curve of the real beam is obtained. 


\section{Results}

\subsection{Simply Supported Beam}

In presented numerical examples equation (2a) is applied.

Example 1 As an example, the task is to determine numerically the elastic curve of cantilevered simply supported beam shown in Figure 2.

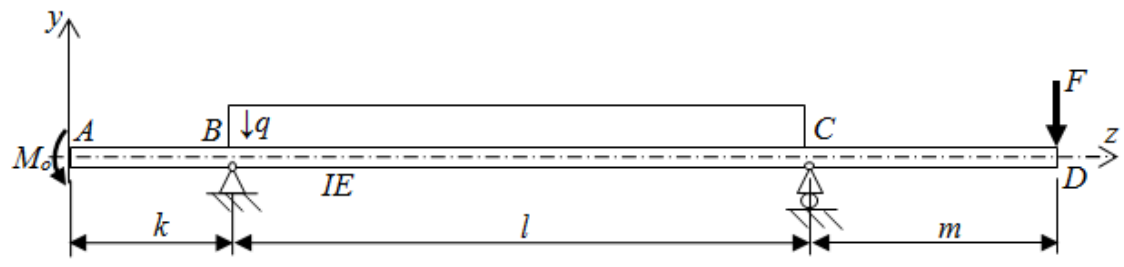

Figure 2

Cantilevered simply supported beam

The following numerical data are given: $F=2000 \mathrm{~N}, \mathrm{q}=4000 \mathrm{~N} / \mathrm{m}, \mathrm{M}_{\mathrm{o}}=4000 \mathrm{Nm}$, $\mathrm{k}=1000 \mathrm{~mm}, \mathrm{l}=3500 \mathrm{~mm}, \mathrm{~m}=1500 \mathrm{~mm}, \mathrm{E}=210 \mathrm{GPa}, \mathrm{I}=328 \mathrm{~cm}^{4}$.

For the given numerical values the reaction forces of the supports:

$$
\begin{aligned}
& F_{B}=\frac{1}{l}\left(M_{o}+\frac{q}{2} l^{2}-F m\right), \\
& \mathrm{F}_{\mathrm{C}}=\frac{1}{l}\left(F(l+m)-M_{o}-\frac{q}{2}\left(k^{2}-(l+m)^{2}\right),\right.
\end{aligned}
$$

while the moment $(\mathrm{z})$ function is plotted in Figure 3.

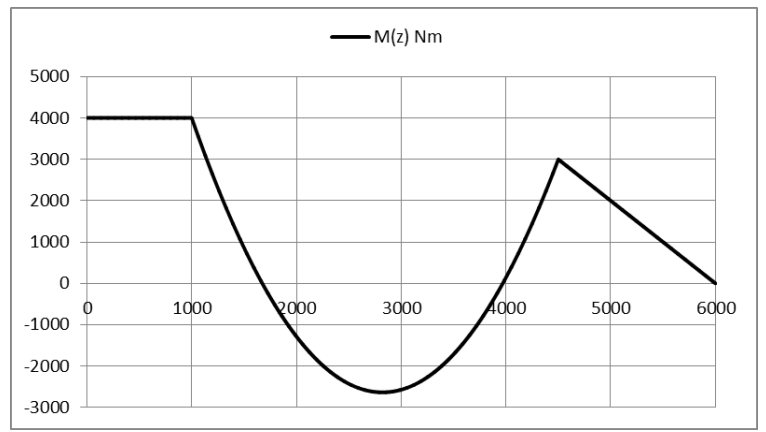

Figure 3

Moment function(z) of the cantilevered simply supported beam 
Three segments along the beam are evident and the differential equations according to (2a) of the elastic curve for each segment are formed. The obtained relations are

$0 \leq \mathrm{z} \leq \mathrm{k}, \quad \mathrm{y}_{1}^{\mathrm{n}}=-\frac{\mathrm{M}_{\mathrm{o}}}{\mathrm{IE}}\left(1+\mathrm{y}^{\prime 2}\right)^{\frac{3}{2}}$

$\mathrm{k} \leq \mathrm{z} \leq \mathrm{k}+\mathrm{l}$,

$y_{2}^{\prime \prime}=-\frac{1}{I E}\left(\frac{q}{2} z^{2}-\left(\frac{q}{2} l+\frac{M_{0}-F m}{l}+q k\right) z+M_{o} \frac{1+k}{l}-\frac{F m k}{l}+\frac{q}{2} k^{2}+\frac{q}{2} l k\right)\left(1+y^{\prime 2}\right)^{\frac{3}{2}}$

$\mathrm{k}+\mathrm{l} \leq \mathrm{z} \leq \mathrm{k}+\mathrm{l}+\mathrm{m}, \quad \mathrm{y}_{3}^{\mathrm{n}}=-\frac{\mathrm{F}}{\mathrm{IE}}(\mathrm{k}+\mathrm{l}+\mathrm{m}-\mathrm{z})\left(1+\mathrm{y}^{\prime 2}\right)^{\frac{3}{2}}$

Let us solve the above-mentioned equations numerically for initial values $\mathrm{y}_{\mathrm{o}}=0$ and $\mathrm{y}_{\mathrm{o}}=0$. Namely, it is assumed that the left end of the beam is fixed and corresponds to a cantilever. Therefore, the moment function as a function of coordinate $\mathrm{z}$ does not yet correspond with the original beam. The obtained result is plotted in Figure 4.

Obviously the shape of the elastic curve is not suitable to the original loading and the constraint relations. In order to get the accurate initial values let us carry out the following transformations.

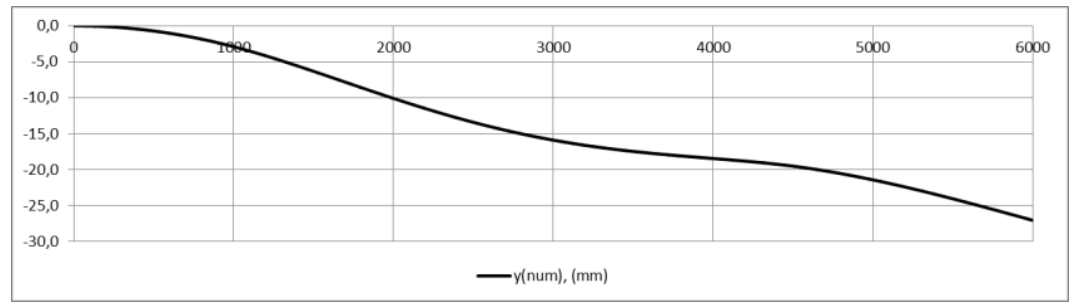

Figure 4

Elastic curve, as a function of $\mathrm{z}$, of the cantilever for initial conditions $\mathrm{y}^{\prime} \mathrm{o}=0$ and $\mathrm{yo}^{\mathrm{o}}=0$

Rotation around axis perpendicular to xy plane

Creating the ratio of differences between deflections of cross-sections $\mathrm{B}$ and $\mathrm{C}$ and between their positions coordinates an angle can be obtained as follows:

$\varphi=\frac{\mathrm{y}_{\mathrm{C}}-\mathrm{y}_{\mathrm{B}}}{\mathrm{z}_{\mathrm{C}}-\mathrm{z}_{\mathrm{B}}}=\frac{-19,52532706 \mathrm{~mm}-(-2,90391530) \mathrm{mm}}{4500 \mathrm{~mm}-1000 \mathrm{~mm}}=-0,0047489747 \mathrm{rad}$.

This angle with opposite sign can be treated as initial inclination of cross-section A, i.e.

$y_{\mathrm{A}}^{\prime}=-\varphi=0,0047489747 \mathrm{rad}$. 
The numerical calculation of differential equations of the elastic curves is repeated with initial values:

$\mathrm{y}_{\mathrm{A}}=0, \mathrm{y}_{\mathrm{A}}^{\prime}=0,0047489747 \mathrm{rad}$.

The obtained elastic curve is plotted in Figure 5.

It can be noticed that for initial conditions (15) the values of deflection at supports $B$ and $C$ are equal: $y_{B}=y_{C}=1,84504132 \mathrm{~mm}$. After this recognition translation along axis y seems obvious.

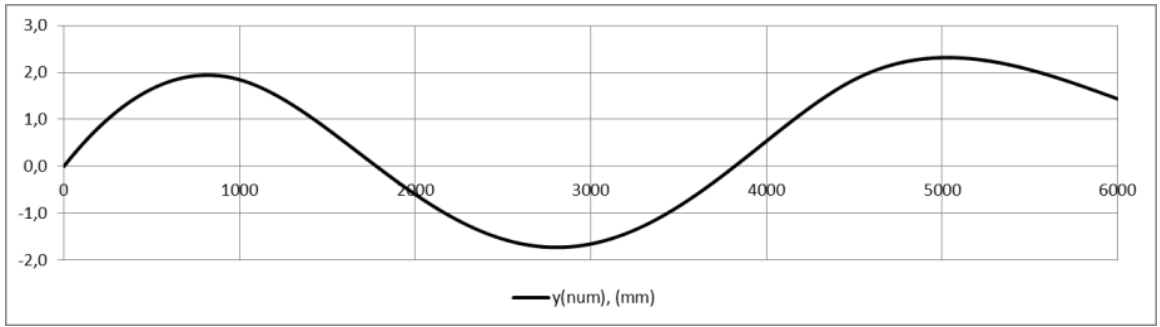

Figure 5

Elastic curve for initial values: $y_{A}=0 \mathrm{~mm}, y_{A}^{\prime}=0,0047489747 \mathrm{rad}$

Translation along axis y

Now, the curve is translated along y axis for the value

$y_{A}=-y_{B}=-y_{C}=-1,84504132 \mathrm{~mm}$, to move the supports in the position with zero deflection. Starting with numerical procedure and applying the calculated initial values $\mathrm{y}_{\mathrm{A}}=-1,84504132 \mathrm{~mm}, \quad \mathrm{y}_{\mathrm{A}}^{\prime}=0,0047489747 \mathrm{rad}$ the elastic curve of the beam are obtained and plotted in Figure 6. In order to check the obtained results the Betti-theorem (Table 3) is applied. Results obtained in different ways are compared to each other and summarized in Table 3.

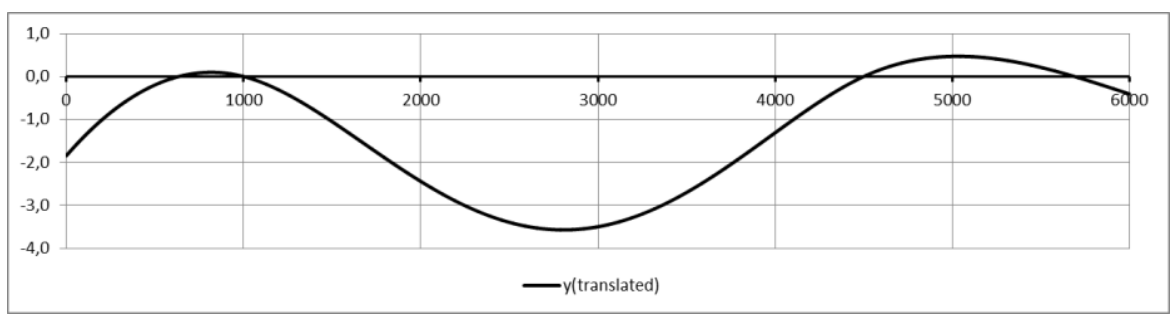

Figure 6

Elastic curve determined based on numerically and analytically obtained initial conditions 


\subsection{Cantilevered Simply Supported Beam having Sinusoidal Variable Circular Cross-Section}

Example 2 The sketch of the cantilevered simply supported beam can be seen in the previous example. In this case, there is a beam having variable circular crosssection (Figure 7). Its diameter is described by equation $d(z)=100+30 \sin (0.004712 z)[\mathrm{mm}]$. Other input data are the same.

Starting with numerical procedure again and applying the calculated initial values $\mathrm{y}_{\mathrm{A}}=-2,98325081 \mathrm{~mm}, \mathrm{y}_{\mathrm{A}}^{\prime}=0,00433389 \mathrm{rad}$ the elastic curve of the beam is obtained and plotted in Figure 8. In order to check the obtained results the Bettitheorem is applied

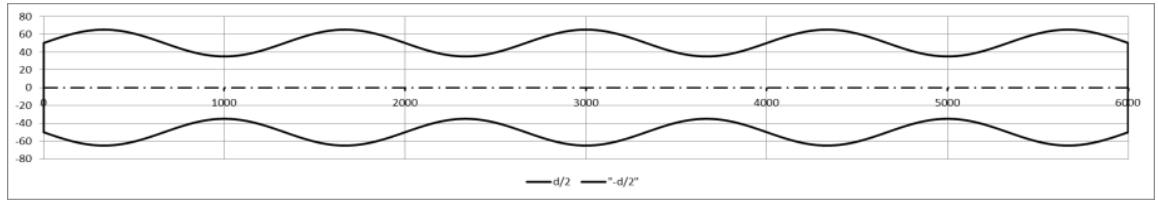

Figure 7

Shape of the simply supported beam having variable circular cross-section (side view)

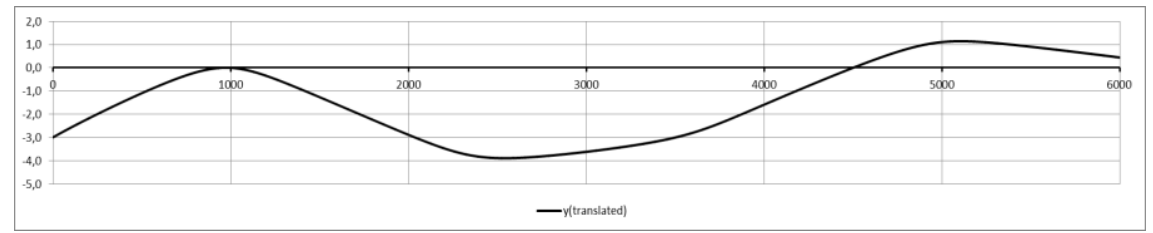

Figure 8

Elastic curve determined and based on obtained initial conditions

Results obtained in different ways are compared to each other and summarized in Table 3. Comparing the results obtained numerically for the nonlinear model and analytically for the linearized system (Betti-theorem) it can be concluded that the difference between them is negligible, moreover it can be seen the effect of nonlinearity is negligible as well.

Table 3

Comparison of deflections of cross-sections A and D obtained in different ways

\begin{tabular}{lcc}
\hline Example $\mathbf{4 . 1}$ & $\mathbf{y}_{\mathbf{A}}, \mathbf{~ m m}$ & $\mathbf{y}_{\mathbf{D}}, \mathbf{~ m m}$ \\
\hline $\begin{array}{c}\text { Numerical transformation method } \\
\text { - rotation and translation }\end{array}$ & \\
$\begin{array}{l}\text { - transformation of the boundary } \\
\text { value problem into the initial value } \\
\text { problem }\end{array}$ & -1.8452 & $-0,4083$ \\
\hline $\begin{array}{l}\text { Betti-theorem for beams of variable } \\
\text { cross-section }\end{array}$ & -1.8398 & $-0,4127$ \\
\hline
\end{tabular}




\begin{tabular}{ccc}
\hline Example $\mathbf{4 . 2}$ & $\mathbf{y}_{\mathbf{A}}, \mathbf{m m}$ & $\mathbf{y}_{\mathbf{D}}, \mathbf{m m}$ \\
\hline $\begin{array}{c}\text { Numerical transformation method } \\
\text { - rotation and translation }\end{array}$ & & \\
- transformation of the boundary \\
$\begin{array}{c}\text { value problem into the initial value } \\
\text { problem }\end{array}$ & $-2,9832$ & 0,4438 \\
\hline $\begin{array}{c}\text { Betti-theorem } \\
\text { for beams of variable cross-section }\end{array}$ & $-2,9830$ & 0,4408 \\
\hline
\end{tabular}

\subsection{Cantilevered Statically Indeterminate Beam to the First- Degree having Variable Circular Cross-Section}

Example 3. As third example a statically indeterminate beam with three supports, having variable circular cross-section is shown in Figure 9. The task is the same: to determine numerically the elastic curve of the beam. Following numerical data are given: $F_{1}=6000 \mathrm{~N}, F_{2}=16000 \mathrm{~N}, \mathrm{q}=12000 \mathrm{~N} / \mathrm{m}, \mathrm{M}_{\mathrm{o}}=3000 \mathrm{Nm}, \mathrm{a}=1000 \mathrm{~mm}$, $\mathrm{E}=210 \mathrm{GPa}$.

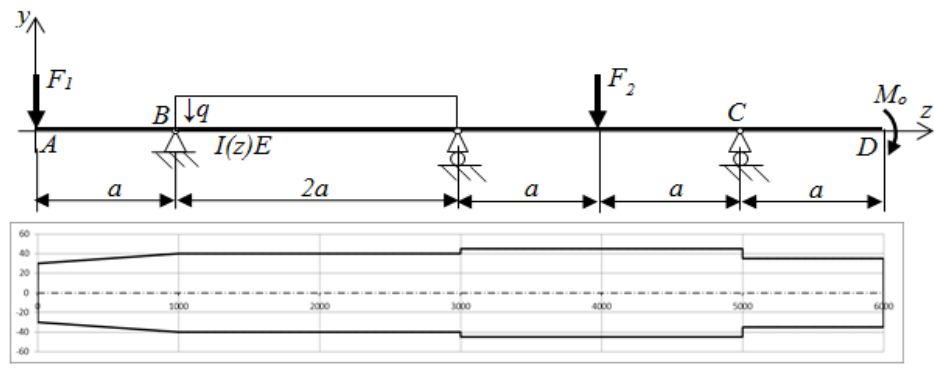

Figure 9

Cantilevered beam with three supports together with the shape of the of the beam having a variable circular cross-section (side view)

As a result of applying the Clapeyron-equation the moment(z) function can be seen in Figure 10.

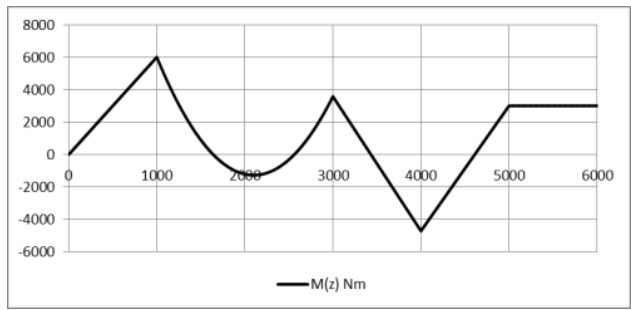

Figure 10

Moment function of the cantilevered beam with three supports 
By applying of above described numerical procedure again, calculated initial values are $\mathrm{y}_{\mathrm{A}}=9,1415991914 \mathrm{~mm}, \mathrm{y}_{\mathrm{A}}{ }=0,01335125 \mathrm{rad}$. Obtained elastic curve of the beam plotted in Figure 11.

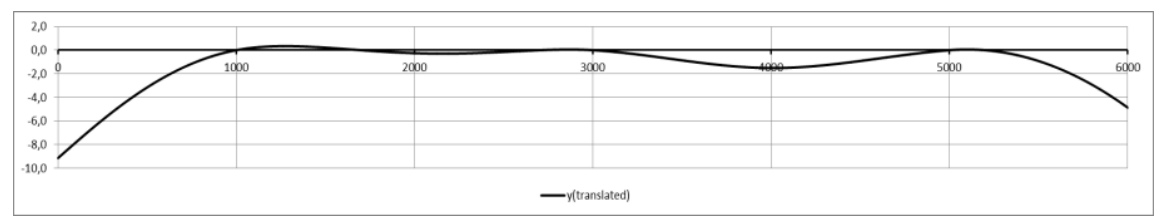

Figure 11

Elastic curve determined and based on obtained initial conditions

\section{Conclusions}

It can be concluded:

- The initial slope of the arbitrary loaded simple supported beam can be determined with high accuracy if the structure is modified into a clamped-free beam. For that case the inclination angle of the free end of the beam is the ratio between the difference of elastic deflections of cross sections in the supporting points of the 'modified beam' and the distance between supports.

- For the case of small deformation when the nonlinearity is weak the suggested procedure for calculation of the inclination angle is applicable with certain accuracy.

- However, if the deformation is large and the nonlinearity is strong serious number of iterative steps are necessary to reach the demanded accuracy.

- Applying the suggested formula for inclination angle the elastic curves of simple supported beams can be determined numerically.

- Based on the suggested procedure the boundary value problem of simple supported and continuous beam is transformed into initial value problem which is a special and effective application of the shooting method. The method is stable and easy to use.

- Results obtained by the method and compared with those obtained with Betti theorem for the linear models show a good agreement. 


\section{Appendix A}

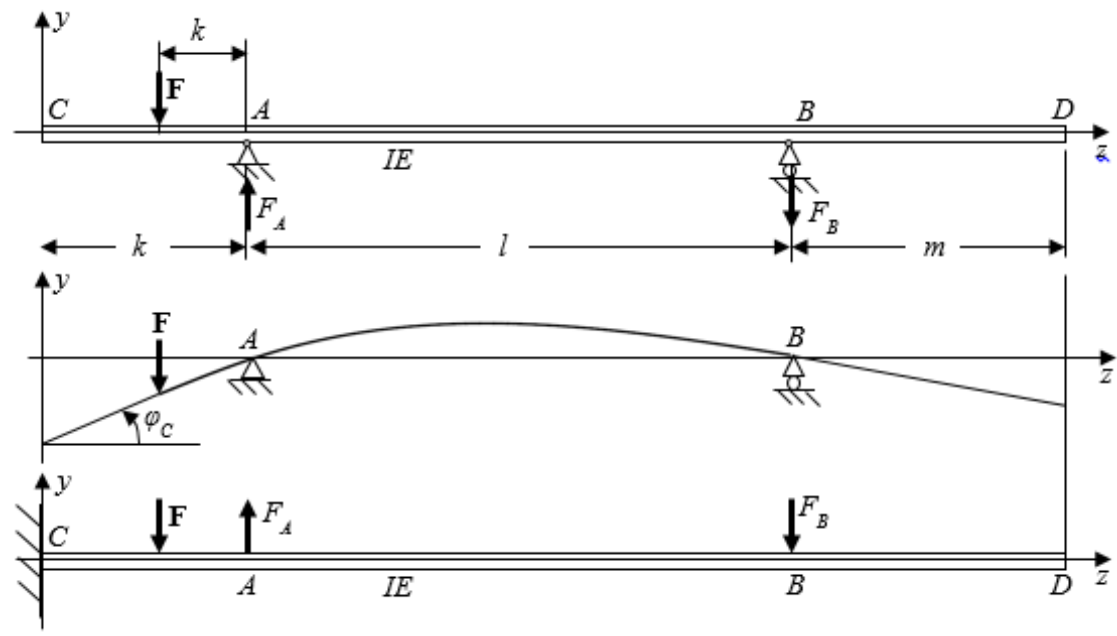

Figure 12

Simple supported beam loaded by concentrated force on the left console at arbitrary place, shape of elastic curve (strong enlargement), moreover sketch of ,,modified” beam, i.e. clamped at cross-section C

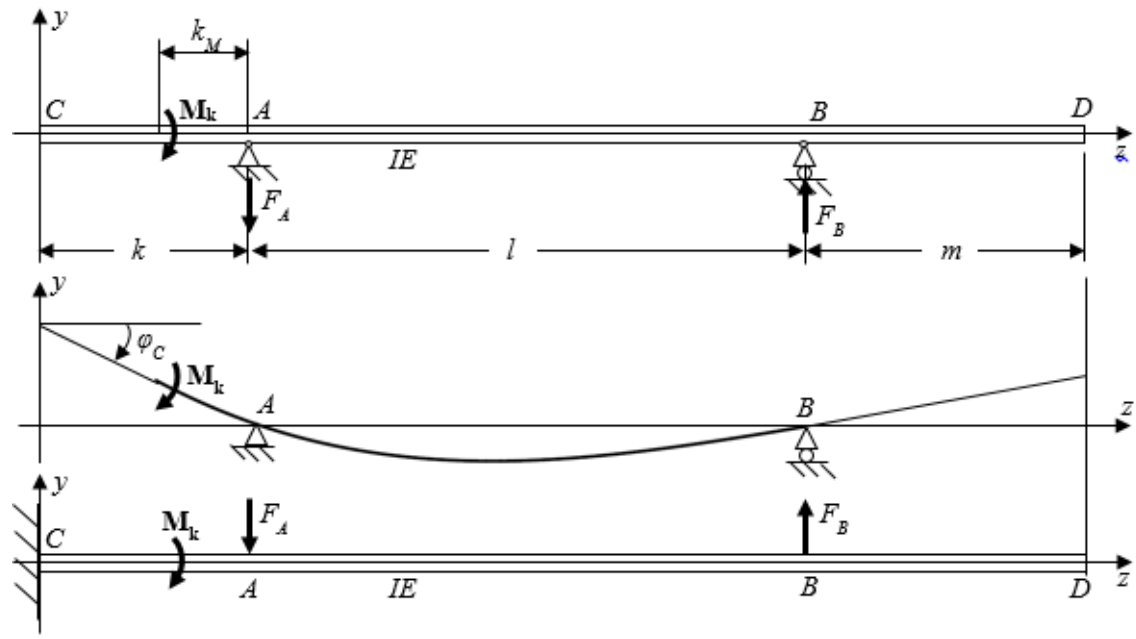

Figure 13

Simple supported beam loaded by couple of force on the left console at arbitrary place, shape of elastic curve (strong enlargement), moreover sketch of ,modified” beam, i.e. clamped at cross-section C 


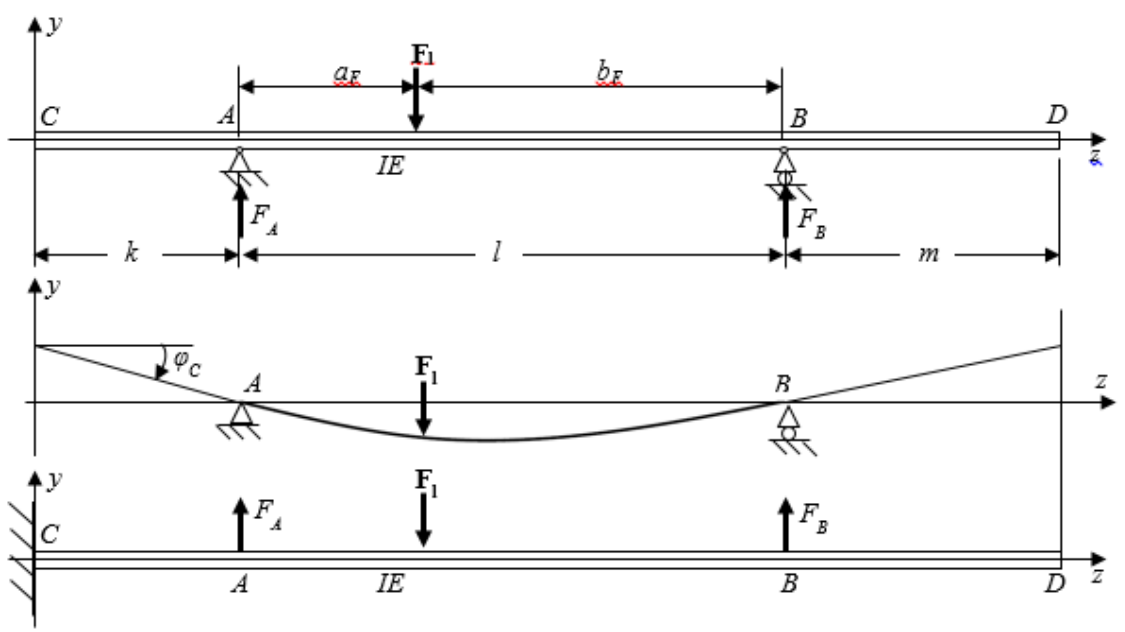

Figure 14

Simple supported beam loaded by concentrated force on effective span at arbitrary place, shape of elastic curve (strong enlargement), moreover sketch of „modified” beam, i.e. clamped at cross-section

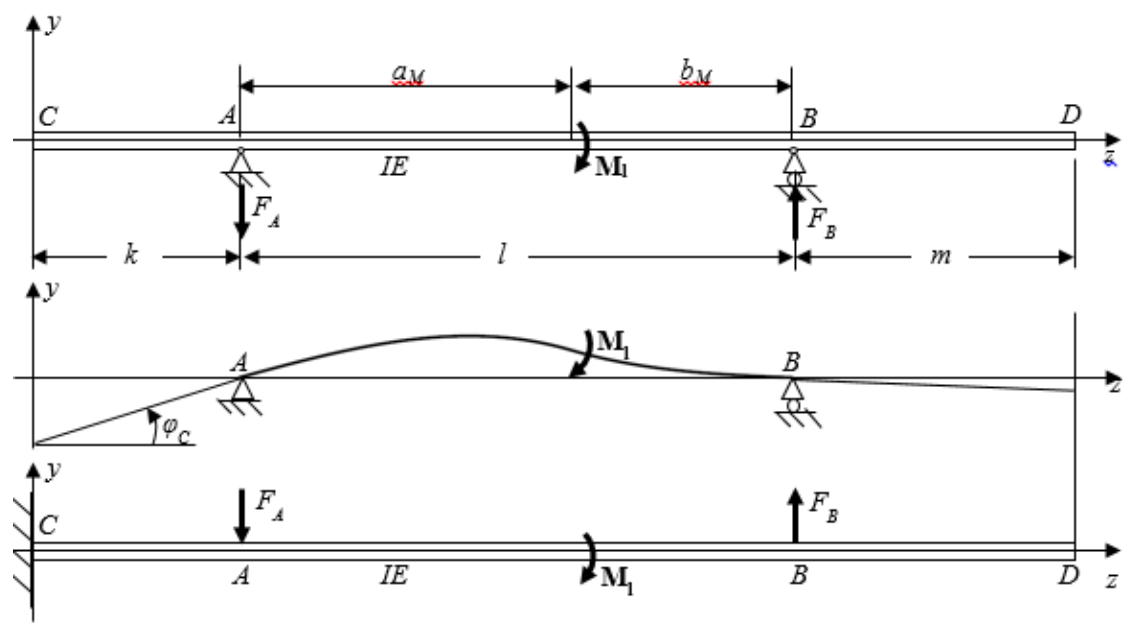

Figure 15

Simple supported beam loaded by couple of force on effective span at arbitrary place, shape of elastic curve (strong enlargement), moreover sketch of ,,modified” beam, i.e. clamped at cross-section C 


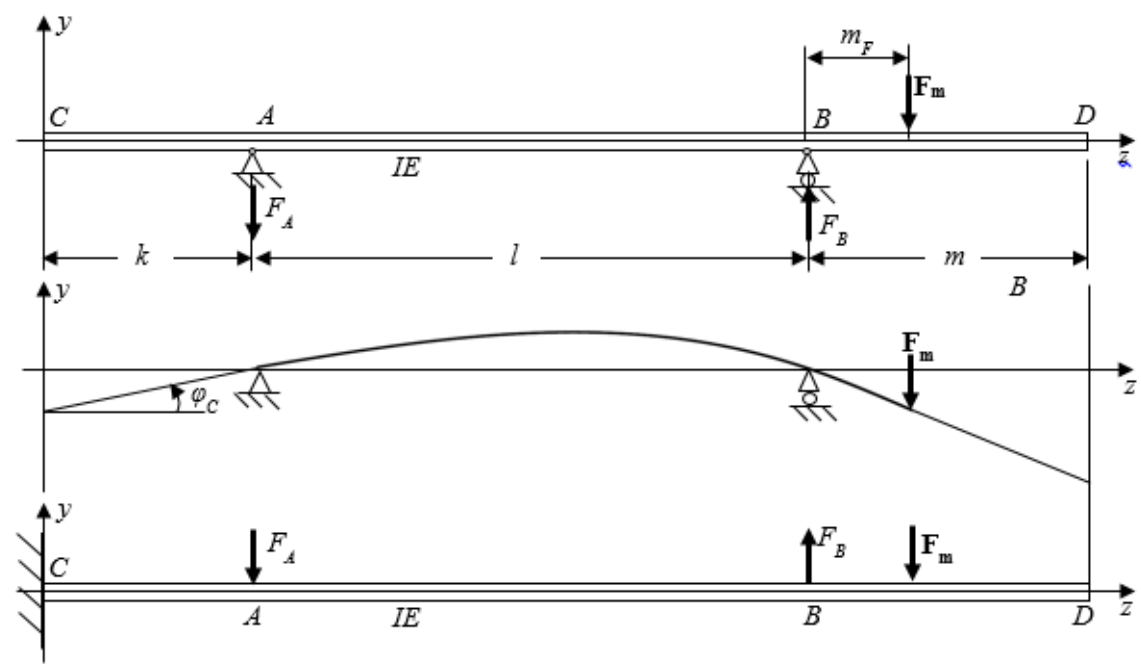

Figure 16

Simple supported beam loaded by concentrated force on the right console at arbitrary place, shape of elastic curve (strong enlargement), moreover sketch of ,modified” beam, i.e. clamped at cross-section C

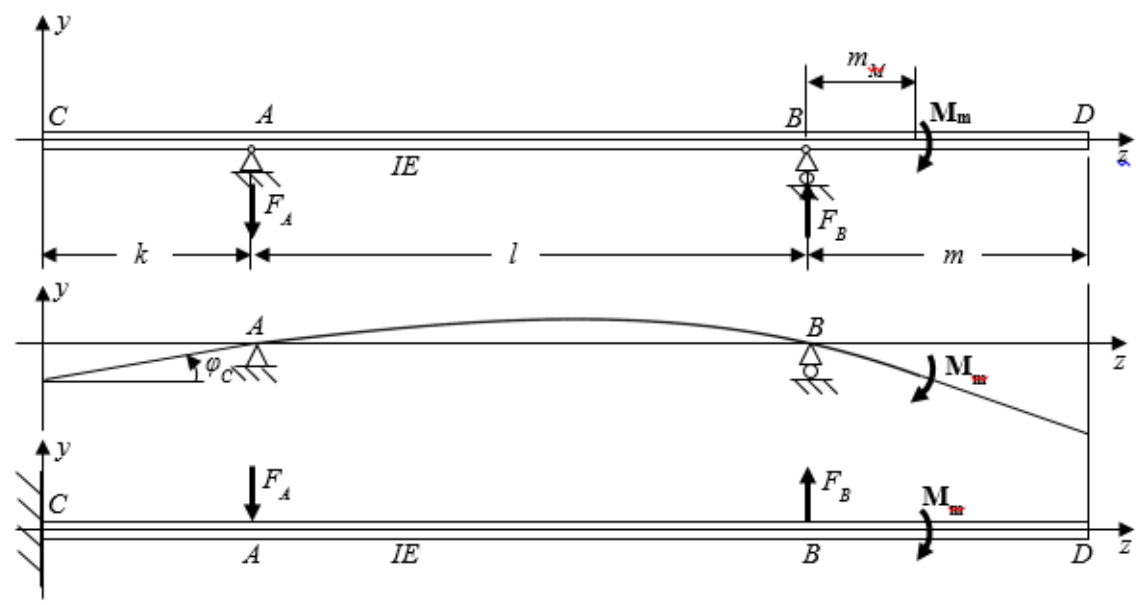

Figure 17

Simple supported beam loaded by couple of force on the right console at arbitrary place, shape of elastic curve (strong enlargement), moreover sketch of ,,modified” beam, i.e. clamped at cross-section $\mathrm{C}$ 

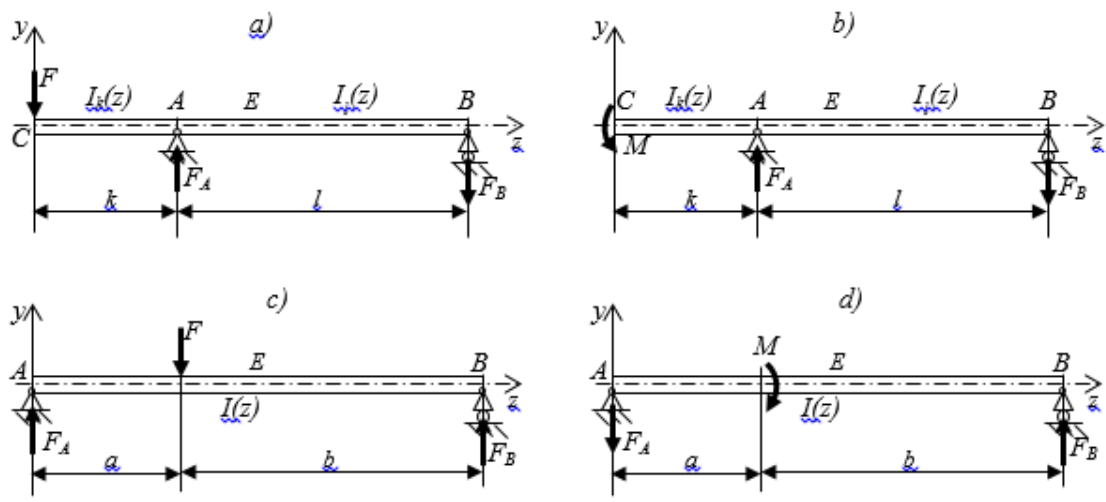

Figure 18 (a-d)

Simple supported beam loaded by concentrated force or couple of forces on the end of the cantilever or between its supports. The moment of inertia of the cross section about its neutral axis is continuous function of position coordinate $\mathrm{z}$

\section{References}

[1] Ibhadode, O.; Dagwa, I.; Asibor, J.; Oho-Oghogho, E. Development of a computer aided deflection analysis (CABDA) program for simply supported loaded beams. Int. J. Eng. Res. Africa 2017, 30, 23-28, https://doi.org/10.4028/www.scientific.net/JERA.30.23

[2] Heng, Z.; Shu-Ying, Q.; Guo-Liang, W. Research on the method of simply supported beam modal parameters recognition by QY inclinometer. J. Appl. Sci 2014, 14, 1844-1850, https://doi.org/10.3923/jas.2014.1844.1850

[3] Yang, N.; Qin, S. Effect of quite-inclination angles on structural performance of Tibetan Timber beam-column joints. J. Perform. Constr. Facil. $\mathbf{2 0 1 8} 32, \quad 12$ p, https://doi.org/10.1061/(ASCE)CF.19435509.0001156

[4] Rojas, A. L.; Chavarria, S. L.; Elizonda, M. M.; Kalashnikov, V. V. A mathematical model of elastic curve for simply supported beams subjected to a concentrated load taking into account the shear deformations. Int. J. Innov. Comput. Inf. Control., ICIC Exp. Lett., Part B: Appl. 2016 12, 41-54

[5] Ramachandra, L. S.; Roy, D. The locally transversal linearization (LTL) method revisited: A simple error analysis J. Sound Vib. 2002, 256, 579-589, https://doi.org/10.1006/jsvi.2001.4222

[6] Kumar, R., Ramachandra, L. S., Roy, D. A multi-step linearization techniques for a class of bending value problems in non-linear mechanics Comput. Mech. 2006, 39, 73-81, https://doi.org/10.1007/s00466-005-00096 
[7] Viswanath, A.; Roy, D. Multi-step transversal and tangential linearization methods applied to a class of nonlinear beam equations Int. J. Solids. Struct. 2007, 44, 4872-4891, https://doi.org/10.1016/j.ijsolstr.2006.12.008

[8] Merli, R.; Lázaro, S.; Monleón, S., Domingo, A. Comparison of two linearization schemes for the nonlinear bending problem of a beam pinned at both ends Int. J. Solids. Struct. 2007, 47, 865-874, https://doi.org/10.1016/j.ijsolstr.2009.12.001

[9] Thankane, K. S.; Stys, T. Finite difference method for beam equation with free ends using Mathematica SAJPAM 2009, 4, 61-78

[10] Bíró, I.; Cveticanin, L.; Szuchy. P. Numerical method to determine the elastic curve of simply supported beams of variable cross-section' Struct. Eng. Mech. Int. J. 2018, 68, 713-720, https://doi.org/10.12989/sem.2018.68.6.713

[11] Abu-Alshaikh, I.; Alkhaldi, H.; Beithou, N. Large deflection of prismatic cantilever beam exposed to combination of end inclined force and tip moment Mod. Appl. Sci. 2018, 12, 98-111, https://doi.org/10.5539/mas.v12n1p98

[12] Batista, M. Large deflection of a beam subject to three-point bending Int. J. Non-Linear Mech. 2015, 69, 84-92, https://doi.org/10.1016 /j.ijnonlinmec.2014.11.024

[13] Abolfathi, A.; Brennan, M. J.; Waters, T. Large deflection of simply supported beam, ISVR Technical Memorandum No. 988, University of Southampton, 2010

[14] Hatami, M.; Vahdani, S.; Ganji, D. D. Deflection prediction of a cantilever beam subjected to static co-planar loading by analytical methods HBRC J. 2014 10, 191-197, https://doi.org/10.1016/j.hbrcj.2013.11.003

[15] Batista, M. Analytical solution for large deflection of Reissner's beam on two supports subjected to central concentrated force Int. J. Mech. Sci 2016, 107, 13-20, https://doi.org/10.1016/j.ijmecsci.2016.01.002

[16] Machado, J. A. T.; Babaei, A.; Moghaddam, B. P. Highly Accurate Scheme for the Cauchy Problem of the Generalized Burgers-Huxley Equation. Acta Polytechnica Hungarica Vol. 13, No. 6, 2016, 183-195, DOI: 10.12700/APH.13.6.2016.6.10

[17] Horváth, L.; Rudas, I. J. Modeling and Problem Solving Techniques for Engineers. Elsevier Academic Press, 2004, London, ISBN 9780126022506

[18] Cveticanin, L.; Mester, Gy. Theory of Acoustic Metamaterials and Metamaterial Beams: An Overview. Acta Polytechnica Hungarica, Vol. 13, No. 7, 2016, 43-62, DOI: 10.12700/APH.13.7.2016.7.3 